\title{
THE STATE AS INTERACTING WITH THE MARKET - A SUITABLE CONTEXT FOR THE NONPROFIT SECTOR
}

\author{
Andreea-Angela ȘEULEAN (VONȚEA) \\ Bucharest University of Economic Studies, Bucharest, Romania \\ andreea.vontea@mk.ase.ro
}

\begin{abstract}
The paper aims to contextualize the elements that define the peculiarities of the nonprofit nonprofit sector. In a general note, there is provided a series of answers to the following questions: 'Which ones are the factors that influenced the establishment of the nonprofit sector?', and 'Of what consists the object of the conceptual delineations regarding the nonprofit sector?'. In a particular sense, the first part of the paper refers primarily to the aspects regarding the necessity to optimize the manner of organizing the society, along with the one related to the establishment of a distinctive framework in terms of organizational infrastructure of the civil society. The second part of the paper begins with the structural-operational definition of the nonprofit sector and continues with its general characteristics.
\end{abstract}

Keywords: Nonprofit sector, Nonprofit organizations, Structural-operational definition

\section{INTRODUCTION}

Concerning the historical context associated to the term of 'independent sector', Anheier \& List (2005) evoke the fact that it appeared in the United States of America during in the 1980s, its meaning referring to the role played by the charitable organizations and foundations (i.e. nonprofit organizations) from the perspective of acquiring of a 'third force' manifested outside from the sphere of action of the government, respectively of the private sector. However, the presence of different critiques formulated for the term was inherent, as many nonprofit organizations are considered to be way too far from being independent, regardless of whether the political of the financial approach is discussed. From a political viewpoint, many of these entities are involved in advocacy activities which, in their turn, are related to the interests that possess a distinctive status of which they are conditioned in order to be supported. In financial terms, the obtained income depends to a large extent on both the conduct of government and business environment. 


\section{OPTIMIZING THE MANNER OF SOCIETY'S ORGANIZATION}

The nonprofit sector represents the sum of the private, voluntary and nonprofit organizations and associations. It describes a set of organizations and activities that are located in the immediate vicinity of government, state and public sector, on one hand, and the business sector, on the other hand. Sometimes entitled 'the third sector', along with the government and its public administration agencies as forming the first one and the world of business of trade as forming the second one, the sector in cause is one that has gained prominence in recent years. Welfare provision, education, community development, international relations, the environment or art and culture are some of the fields most commonly associated with it (Anheier, 2005).

As a preamble of understanding the rationale behind the existence of nonprofit organizations, Oster (1995, p. 18) asks: 'What are the advantages of a nonprofit-making organization in relation to the opposed entities operating in the public sector, namely profit-oriented?'. In this regard, the answer refers to the fact that, in order to design their own mission, the organizations concerned should consider how they can use the benefits they have.

Even though, in the generic sense, the form of 'nonprofit' sector is being used, suggesting clearly defined limits for the public sector and for the profit-oriented one, in reality these cross-sectorial differences are somewhat unclear. Organizations tend to 'migrate' from one sector to another as, in general terms, the transition from public to nonprofit, or from nonprofit to 'for profit' can be made. Other entities can integrate both 'profit' and 'nonprofit' forms, while there are cases where quasi-governmental institutions are located in an intermediary plan between private and public domains (Anheier, 2005).

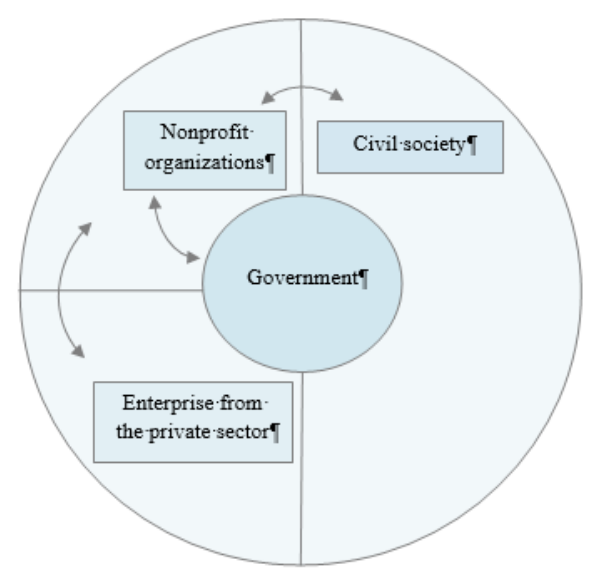

FIGURE 1. THE ROLE OF NONPROFIT ORGANIZATIONS IN SOCIETY Source: Adapted from Sargeant, 1999. 
Figure 1 illustrates how nonprofit organizations are currently an integral part of the composition of many companies. They have strong links with civil society at the level of which they can be able to provide essential goods and services for those in need or disadvantage. They will also have contacts with the government, as they lobby for attention, request funding, compete for government contracts etc. In addition, nonprofit organizations can have close links with business organizations both on the basis of the supply of goods and services, and from the perspective of the funding request on behalf of the beneficiary groups. However, it should not be circumvented that the represented model is practically a gross simplification of reality from the perspective of the complexity of relationships and the importance of the role associated with the nonprofit sector (Sargeant, 1999).

\section{ESTABLISHING A DISTINCTIVE FRAMEWORK AS AN ORGANIZATIONAL INFRASTRUCTURE OF CIVIL SOCIETY}

An important approach to clarifying the concepts discussed above belongs to Anheier (2005) which distinguishes between the macro- - specific level of civil society and the meso- - specific of the nonprofit sector. At the same time, the social capital is a micro- level concept describing a set of individual actions and characteristics. However, they also overlap in a number of representative ways so that the nonprofit sector, together with its many groups (e.g., associations and organizations), can be understood as the civil society infrastructure of whose micro-social foundation is ensured by the notion of social capital. In other words, these concepts are the pillars of an approach that seeks to penetrate beyond the 'state vs. market' perspective that dominated the thinking and creation of policies from the social sciences field for a considerable period of the 20th century.

In a context largely related to the procurement of resources and regulations related to the issue of no distribution of profits, there is a set of distinctive elements between the three economic sectors. Nonprofit entities operate under a no distributive constraint that prohibits the distribution of profits made to management. The ban on the distribution of profits contrasts strongly with the lucrative model, where shareholders expect to have a certain percentage of the total value of the profits earned. Given that philanthropic organizations largely depend on donor generosity, one can see how perceptions of a nonprofit organization as ethical relate directly to its viability (Barrett, 2011).

The overall relational framework presented in Figure 2 is made up of three bidirectional components: the relationship between government and civil society, the relationship between government and business, and, last but not least, it integrates the relationship between civil society and the business world. Each of the three types of relationships can follow either direction, as indicated by the '[+/-]' (Kotler \& Lee, 2009). 


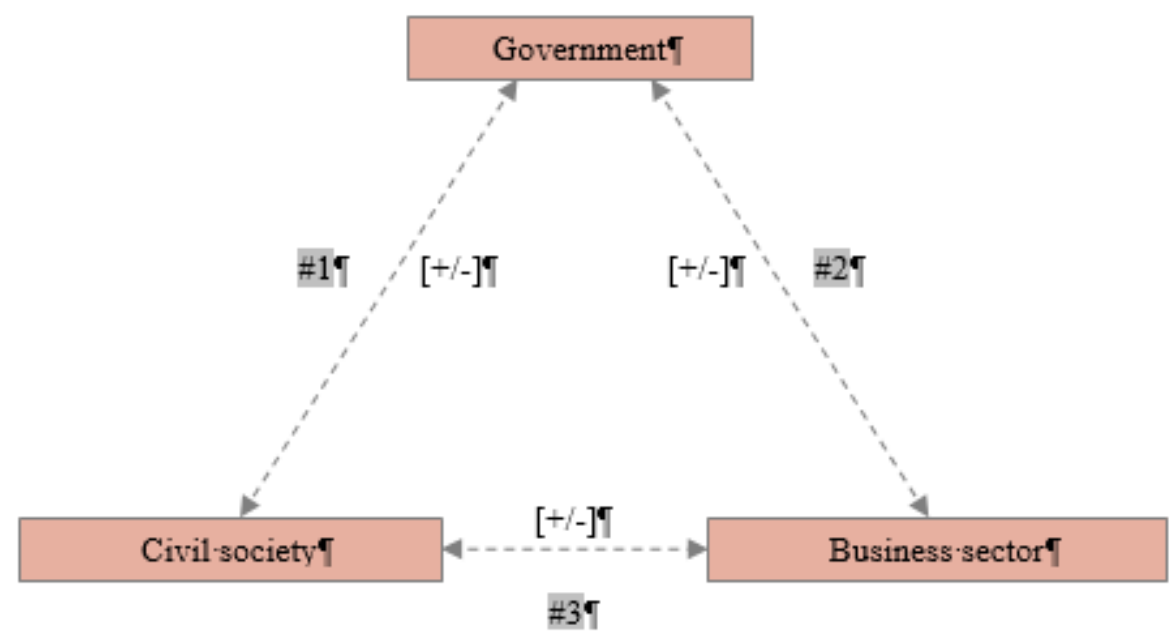

FIGURE 2. THE THREE-WAY RELATIONSHIP BETWEEN GOVERNMENT, CIVIL SOCIETY AND THE BUSINESS SECTOR, WITH ITS THREE BIDIRECTIONAL RELATIONSHIPS Source: Adapted from Kotler \& Lee, 2009, p. 315.

The analysis of the potential relationships between nonprofit organizations and government reveals an increase in the gap between the perceived social need and government capabilities, which translates itself into the expansion of nonprofit activities. According to Weisbrod (1998), from the perspective of any nonprofit organization, the need for its subsequent activity depends on the size of the aggregate problem and on the extent to which the government entity intervenes, a situation in which the level of involvement of the other active organizations should not be neglected. In addition, the argument put forward by Bahmani, Galindo \& Méndez (2012) highlights the idea of complementarity, as it states that the role played by NGOs in society is relevant in terms of their attempts to meet human needs in a different way or as a complement of lucrative organizations and governmental activities respectively. In relation to the interconnected elements depicted in Figure 3, Paton (2009 cited in Alcock, 2010) refers to a set of principles and values associated with each of them as follows: State - formality, regulation, coercion, redistribution; Market - Entrepreneurship, investment, accumulation, competition; Civil society - association, reciprocity, altruism, democracy. 


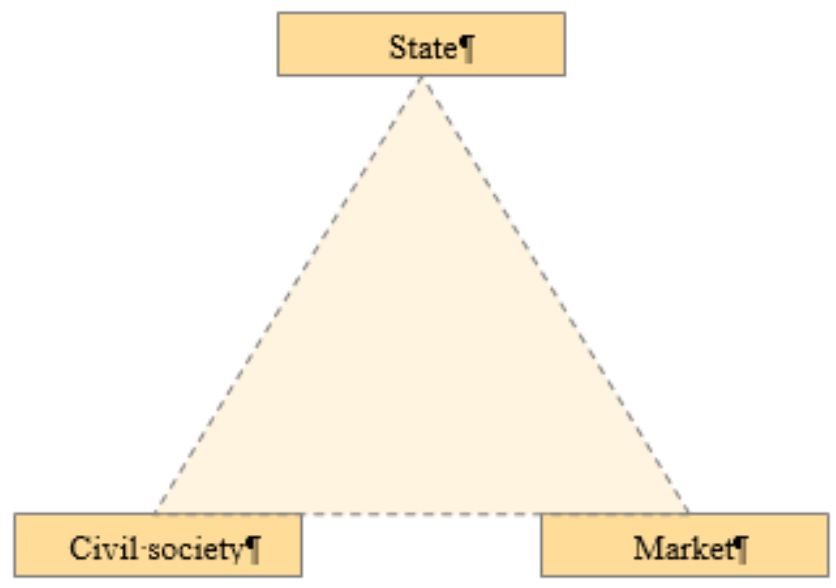

FIGURE 3. THE MODEL OF THE THREE SECTORS

Source: Adapted from Paton, R. (2009). (Towards) a sedimentary theory of the third sector. In NCVO/VSSN Annual Research Conference. Warwick, Great Britain, 7-8 September 2009. In Alcock, 2010, p. 8.

Anheier \& List $(2005$, p. 54) observe that the conceptual definition of the notion of 'civil society' is presented in various forms and there can be no reference to a unanimous opinion on its precise meaning, although there are many overlaps among the most important conceptual components. Generally speaking, the definitions vary in terms of the emphasis they put on some features of civil society in relation to others. Thus, some definitions focus primarily on issues of state, political and individual freedom, while others assign a greater degree of importance to economic functions and to notions of social capital, namely cohesion. However, a certain reference may be made to the existence of a consensus on the general terminology on civil society, as follows: '[Civil society is] the sum of institutions, organizations and individuals located between the family, the state and the market, in which people associate voluntarily to advance common interests'.

A more concise definition of civil society and which emphasizes the idea of differentiation is the one formulated by Hafford-Letchfield (2009, p. 146): 'Groups of people who form informal organizations as an alternative sector to government or business'. Not least, Patrick (2011, p. 923) affirms that civic participation in civil society contributes to the foundation of social capital, defining it as being: 'the ability of people to act together to meet community needs, solve public problems, and improve community life'. 


\section{THE STRUCTURAL-OPERATIONAL DEFINITION OF THE NONPROFIT SECTOR}

Over the years, many authors have developed a terminology that varies in many respects for what, apparently, is the same general category of organizations. Names such as 'third sector', 'independent sector', 'nonprofit sector', 'charity/volunteer sector' are used with a varying frequency in different countries. Sargeant, Shang \& Associates (2010) recall the shortcomings of this situation, marked by the use of interchangeable names too often and with varying nuances of meaning, making it impossible for any two authors to refer to the same thing.

Salamon (2010) distinguishes between four types of definitions identified in the literature, namely legal, economic, normative and functional definitions.

- Legal definitions probably have the highest occurrence frequency. They define civil society organizations, or what exactly corresponds to the entities in question relative to given national contexts in terms of legal forms or the treatment applied regarding taxes. Such definitions have greater clarity in concrete state structures, but in terms of the international comparative approach their meaning becomes difficult to be addressed.

- The economic definitions have a high degree of linkage to various international statistical systems, presented in two distinct forms. One identifies civil society organizations in terms of targeting any surplus they can generate. A very common form of these definitions is to ban the distribution of any surplus that the organization can earn among its managers, directors, or members. The other form of definitions is allocated to both the corporate and the government sector according to the main source of revenue - taxes and sales, or government grants. The first category of these economic definitions has the advantage of making a clear distinction between civil society organizations and the activities of profit-oriented organizations.

- A third category comprises the normative definitions and focuses on the goals pursued by organizations. Thus, organizations that promote the public good, encourage civic accountability and participation, meet basic human needs or promote solidarity are considered to be valid civil society organizations.

- The definitive set, namely the one of functional definitions, extends the meaning of the civil society concept to include not only organizations, but also certain types of individual activities, especially those that refer to various forms of civic action. This conceptualization extends the concept of civil society not only to the actual participation in civil society organizations, but also to mass social movements, popular demonstrations and other individual forms of civic action. 
Following the analysis of the four previously defined categories of definitions, a consensus has emerged on five structural-operational characteristics that have become what has been called the 'structuraloperational definition' of the sector that integrates nonprofit institutions - Figure 4.

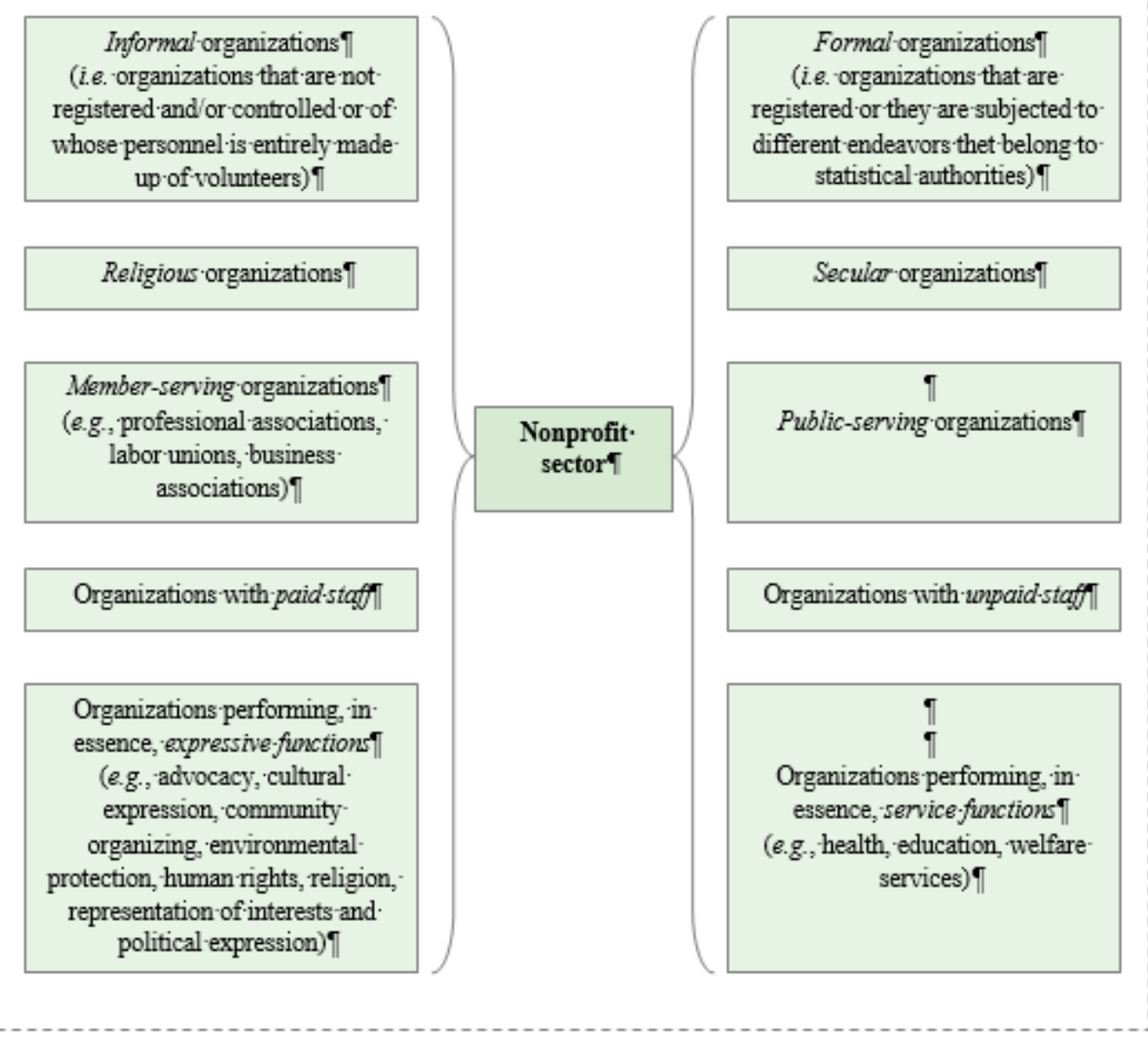

FIGURE 4. DEFINITION OF THE NONPROFIT SECTOR

Source: Author's representation and adaptation from Salamon, 2010, pp. 178-9.

According to the above-mentioned definition formulated Salamon (2010), the nonprofit sector is made up of entities characterized by the following aspects:

- Organizations - i.e. they have a certain structure and some regularity of operations, even if they are formally or legally registered.

- Private - i.e. they are state-separated from an institutional point of view, even if they can receive support from governmental sources. 
- Not profit-distributing - i.e. they are not primarily commercial by the nature of the intended purpose and do not distribute the profits they may generate to the holders or members. Nonprofit institutions may generate surpluses in the course of operations, but any such surpluses must be reinvested in accordance with the organization's objectives.

- Self-governing - i.e. they have their own internal governance mechanisms, are able to carry out operations on their own responsibility and are fundamentally in control of their own activities.

- Non-compulsory - i.e. the membership or participation in the membership depends on the choice or consent of an individual rather than to be required to do so under legal or binding conditions.

\section{CHARACTERIZATION ELEMENTS OF NONPROFIT ORGANIZATIONS}

Yaziji \& Doh (2009) consider that the notion of 'nongovernmental organization' is broad and used somewhat ambiguous to refer to all organizations that are neither an official component of the government nor any private profit-oriented enterprise. However, there is a wide range of NGO types, features and goals within the category.

In order to distinguish between the organizations integrated into the public sector from the ones that belong to the third sector, the latter are sometimes referred to as nongovernmental or no statutory organizations; to be distinguished from the commercial market activity, they are called nonprofit organizations. These negative definitions are widespread and, to a certain extent, correlated with wider political and cultural contexts in which the sector in question is concerned.

The iteration expressed by Evers \& Laville (2004 cited in Alcock, 2010) helps to clarify two defining notions, namely 'NGOs' and 'nonprofit sector', respectively. In the former case, it is often used to refer to international agencies engaging in international development activities, a framework in which it is important that they are separate entities from national government agencies. In the second case, the notion is often used in the United States literature on the sector, in which case the central concern is to distinguish these organizations from the market-oriented approach. This situation can therefore be considered to be a contrasting one with the European literature where public sector relations are more developed and the notion of a non-statutory sector is more common.

The term 'NGO' or 'nongovernmental organization' is used on an international scale in rather inconsistent ways and sometimes confusing. It is a somewhat imprecise term, whose origins belong to the League of Nations (1920s), which has become important within the United Nations system, and is 
now widely used to refer to nonprofit and non-governmental organizations. Their activities are carried out in areas such as international relations, environment, human rights, humanitarian assistance and development of the idea of cooperation. The United Nations system and, similarly, the European Union, the World Bank and the Organization for Economic Co-operation and Development (OECD) recognize the importance of NGOs associated with international affairs by assigning them a consultative status that allows them to express themselves on a range of policy initiatives, to participate in plenary sessions etc. Thus, NGOs have become an instrument by which international organizations are looking for a more socially-politically-oriented participation manifested in a more consistent manner, as a preamble of their own effort to increase the levels of effectiveness and legitimacy (Anheier \& List, 2005).

Nalinakumari \& MacLean (2005) note that the term 'nongovernmental organization' has not been used many times until the formation of the United Nations (UN) since 1945. Within the Charter of the UN, its presence aimed to delimit the participation rights of the specialized intergovernmental agencies by those that belonged to the international private organizations. Another variation of expression is raised by Anheier (2005), who argues that the role of approaching this concept is to describe the organizations concerned within the developing world and relative to international relations, but tends to refer only to a part of what else is considered to be part of this sector, namely organizations involved in promoting social and economic development, predominantly at a basic level.

The term 'nonprofit organization', although often used interchangeably with 'voluntary association', 'charitable organization', 'NGO' or 'third sector organization', is primarily of an economic nature. Therefore, it refers to the behavior in relation to the income of the set of institutions involved (Anheier \& List, 2005). The term 'nonprofit' is slightly confusing in view of the fact that the organizations in question can acquire and even act in such a way as to obtain profit (or, more clearly, a surplus of operation) (Sargeant, Shang \& Associates, 2010). Nonprofit organizations are organizations determined by the mission. They lack the common profit-sharing goal shared by for-profit companies. Instead, nonprofit organizations are working to implement a social mission (Laidler-Kylander \& Simonin, 2009).

Nonprofit organizations are placed in a middle area between profit-making and governmental organizations, performing functions that the other two major sectors do not provide or do not adequately provide (Kotler \& Lee, 2009). The main feature of NGOs, and one of the most important differences compared to profit-oriented organizations, is that the purpose of the former ones resides mainly in maximizing the utility as opposed to doing business by taking into account profit considerations (Bahmani, Galindo \& Méndez, 2012).

The term 'nonprofit organizations/sector' emphasizes that these organizations do not have priority to generate profit for their holders. But these organizations sometimes get profits, i.e. they generate more revenue than what represents the subject of spending in a given year (Anheier, 2005). Brennan \& Brady 
(1999) conclude that all charities, causes, associations, nonprofit financial institutions, and other organizations in which the priority goal is anything other than making profit to be distributed to individuals refers to nonprofit organizations.

A distinctive place for conceptual clarification attempts in the context of organizations comprised within the third sector resides in the argumentation formulated by Martens (2002), which defines NGOs as: 'formal (professionalized) independent societal organizations whose primary aim is to promote common goals at the national or the international level'. NGOs are societal actors, as their origin falls within the private sphere. NGOs promote common goals as they work to promote public goods that their members enjoy and/or benefit from. NGOs can be professionalized because they can have paid staff who have a range of skills acquired through a specific training process but are not profit-oriented. NGOs are independent because they are primarily funded by membership fees and private donations. They can receive funding from official institutions, but only to a limited extent, so they are not under the control of government institutions. NGOs are formal organizations because they have a minimal organizational structure that allows them to ensure a continuous flow of activities. These are limited to headquarters, permanent staff and constitution (and also a distinct legal status recognized in at least one state).

In a more concise register, Lambell et al. (2008) emphasize the notion that nongovernmental organizations do not belong to either the government sector or the profit sector. They represent communities, social and political movements, and special interests of all ideological beliefs and at all geographical levels, starting from the local to the global one. Moreover, according to Anheier \& List (2005), the concept of NGO is too narrow, since, being used in generic terms, especially in developing countries and international development literature, only includes organizations that are explicitly involved in promoting development for social and economic reasons.

\section{CONCLUSIONS}

In conclusion, according to Sargeant (1999), a nonprofit organization can be defined as one that exists to contribute to general improvement of society, based on the allocation of appropriate resources and/or the supply of physical goods and services. Such organizations do not justify their existence by gaining personal profits or gains and, as a result, do not distribute profits or surpluses among shareholders or members. However, they may hire staff and engage in revenue-generating activities designed to assist them in fulfilling their assumed mission.

The purpose that defined the structure of the paper resided in contextualizing the elements that contributed to the individualization of the nonprofit sector. Firstly, the paper referred to a series of 
determinants of the emergence of the nonprofit sector. Secondly, the paper offered a description of the subject under discussion as a matter of conceptual delimitations that characterize the sector.

Beyond these general topics rendered by the content of the paper, its first section emphasized the need to optimize the manner of organizing the society as well as on the need to establish a distinctive context as pillar of the civil society's organizational infrastructure. The second section dealt with the nonprofit sector both from the perspective of the structural-operational definition and the one of its general characteristics.

\section{REFERENCES}

Agard, K.A. (Ed.). (2011). Leadership in nonprofit organizations: a reference handbook. Thousand Oaks, CA: Sage.

Alcock, P. (2010). A strategic unity: defining the third sector in the UK. Voluntary Sector Review. 1(1): 5-24.

Anheier, H.K. (2005). Nonprofit Organizations: Theory, management, policy. Oxon and New York, NY: Routledge.

Anheier, H.K., \& List, R.A. (2005). A Dictionary of Civil Society, Philanthropy and the Non-Profit Sector. London: Routledge.

Bahmani, S., Galindo, M.A., \& Méndez, M.T. (2012). Non-profit organizations, entrepreneurship, social capital and economic growth. Small Business Economics 38(3): 271-281.

Barrett, A. (2011). Issues in Nonprofit Ethics. In K.A. Agard (Ed.), Leadership in nonprofit organizations: a reference handbook (pp. 838-848). Thousand Oaks, CA: Sage.

Brennan, L., \& Brady, E. (1999). Relating to marketing? Why relationship marketing works for not-for profit organisations. International Journal of Nonprofit and Voluntary Sector Marketing. 4(4): 327-337. Hafford-Letchfield, T. (2009). Management and Organisations in Social Work (2nd Edition). Exeter: Learning Matters.

Kotler, P., \& Lee, N.R. (2009). Up an Out of Poverty: The Social Marketing Solution. Upper Saddle River, NJ: Wharton School Publishing.

Laidler-Kylander, N., \& Simonin, B. (2009). How international nonprofits build brand equity. International Journal of Nonprofit and Voluntary Sector Marketing.14(1): 57-69.

Lambell, R., Ramia, G., Nyland, C., \& Michelotti, M. (2008). NGOs and international business research: Progress, prospects and problems. International Journal of Management Reviews. 10(1): 75-92.

Martens, K. (2002). Mission Impossible? Defining Nongovernmental Organizations. Voluntas: International Journal of Volunatry and Nonprofit Organizations. 13(3): 271-285.

Nalinakumari, B., \& MacLean, R. (2005). NGOs: A Primer on the Evolution of the Organizations Thar Are Setting the Next Generation of 'Regulations'. Environmental Quality Management. 14(4): 1-21.

Oster, S.M. (1995). Strategic management for nonprofit organizations: theory and cases. New York, NY and Oxford: Oxford University Press.

Patrick, J.J. (2011). Philanthropy, Civil Society, and Democracy in America. In K.A. Agard (Ed.), Leadership in nonprofit organizations: a reference handbook (pp. 922-928). Thousand Oaks, CA: Sage. Salamon, L. M. (2010). Putting the Civil Society Sector on the Economic Map of the World. Annals of 
Public and Cooperative Economics. 81(2): 167-210.

Sargeant, A. (1999). Marketing Management for Nonprofit Organizations. New York, NY: Oxford University Press.

Sargeant, A., Shang, J., \& Associates (2010). Fundraising principles and practice. San Francisco, CA: Jossey-Bass.

Weisbrod, B.A. (1998). The nonprofit mission and its financing: Growing links between nonprofits and the rest of the economy. In B.A. Weisbrod (Ed.), To Profit or Not to Profit:The Commercial

Transformation of the Nonprofit Sector (pp. 1-22). Cambridge and New York, NY: Cambridge University Press.

Weisbrod, B.A. (Ed.). (1998). To Profit or Not to Profit:The Commercial Transformation of the Nonprofit Sector. Cambridge and New York, NY: Cambridge University Press.

Yaziji, M., \& Doh, J. (2009). NGOs and Corporations: Conflict and Collaboration. New York: Cambridge University Press. 